\title{
Reduced hypertrophy in vitro after chondrogenic differentiation of adult human mesenchymal stem cells following adenoviral SOX9 gene delivery
}

\author{
M. Weissenberger ${ }^{1 *}$ (D, M. H. Weissenberger ${ }^{1,2}$, F. Gilbert ${ }^{1,3}$, J. Groll ${ }^{4}$, C. H. Evans $5^{5}$ and A. F. Steinert ${ }^{1,6}$
}

\begin{abstract}
Background: Mesenchymal stem cell (MSC) based-treatments of cartilage injury are promising but impaired by high levels of hypertrophy after chondrogenic induction with several bone morphogenetic protein superfamily members (BMPs). As an alternative, this study investigates the chondrogenic induction of MSCs via adenoviral genedelivery of the transcription factor SOX9 alone or in combination with other inducers, and comparatively explores the levels of hypertrophy and end stage differentiation in a pellet culture system in vitro.

Methods: First generation adenoviral vectors encoding SOX9, TGFB1 or IGF1 were used alone or in combination to transduce human bone marrow-derived MSCs at $5 \times 10^{2}$ infectious particles/cell. Thereafter cells were placed in aggregates and maintained for three weeks in chondrogenic medium. Transgene expression was determined at the protein level (ELISA/Western blot), and aggregates were analysed histologically, immunohistochemically, biochemically and by RT-PCR for chondrogenesis and hypertrophy.

Results: SOX9 CDNA was superior to that encoding TGFB1, the typical gold standard, as an inducer of chondrogenesis in primary MSCS as evidenced by improved lacuna formation, proteoglycan and collagen type II staining, increased levels of GAG synthesis, and expression of mRNAs associated with chondrogenesis. Moreover, SOX9 modified aggregates showed a markedly lower tendency to progress towards hypertrophy, as judged by expression of the hypertrophy markers alkaline phosphatase, and collagen type $X$ at the mRNA and protein levels.

Conclusion: Adenoviral SOX9 gene transfer induces chondrogenic differentiation of human primary MSCs in pellet culture more effectively than TGFB1 gene transfer with lower levels of chondrocyte hypertrophy after 3 weeks of in vitro culture. Such technology might enable the formation of more stable hyaline cartilage repair tissues in vivo.
\end{abstract}

Keywords: Mesenchymal stem cell, Cartilage, SOX9, Gene therapy, Chondrogenesis, Hypertrophy, Adenovirus, Bone marrow

\section{Background}

Once articular cartilage is injured it has very limited capacity to heal. Mesenchymal stem cells (MSCs) derived from human bone marrow and other sources provide an attractive alternative to chondrocytes for cartilage repair [1]. However, the most appropriate factor or combination

\footnotetext{
* Correspondence: m-weissenberger.klh@uni-wuerzburg.de

'Department of Orthopaedic Surgery, König-Ludwig-Haus, Center for

Musculoskeletal Research, Julius-Maximilians-University, Brettreichstrasse 11,

D-97074 Würzburg, Germany

Full list of author information is available at the end of the article
}

of factors to drive MSCs toward chondrogenesis and stable hyaline neocartilage formation remains to be elucidated [2]. We and others have extensively tested several members of the transforming growth factor (TGF)- $\beta$ superfamily including TGF- $\beta 1$ (encoded by TGFB1), bone morphogenetic protein (BMP)-2, BMP-4, BMP-6 and BMP-7, the fibroblast growth factor (FGF) family or the family of hedgehog proteins (e.g. sonic or indian hedgehog $(\mathrm{SHH}, \mathrm{IHH})$ ) for their potential to induce chondrogenic differentiation of MSCs in vitro [3-5]. For efficient delivery of such growth factors, we have successfully explored

(c) The Author(s). 2020 Open Access This article is distributed under the terms of the Creative Commons Attribution 4.0 International License (http://creativecommons.org/licenses/by/4.0/), which permits unrestricted use, distribution, and reproduction in any medium, provided you give appropriate credit to the original author(s) and the source, provide a link to the Creative Commons license, and indicate if changes were made. The Creative Commons Public Domain Dedication waiver (http://creativecommons.org/publicdomain/zero/1.0/) applies to the data made available in this article, unless otherwise stated. 
the potential of adenoviral gene delivery of TGFB1, BMP2 or $B M P 4$, or $I H H$ for efficient chondrogenic induction of MSC aggregate cultures. Although successful in promoting chondrogenesis, these factors also produced high levels of chondrocyte hypertrophy and apoptosis, which was most abundant for $B M P 2$, but also present in the BMP4, IHH and TGFB1 gene modified cultures [6-8]. Although, insulin like growth factor (IGF) 1 is a known mediator of growth plate development and increases extracellular matrix (ECM) synthesis in chondrocytes, IGF1 gene delivery could not induce chondrogenesis alone in primary MSCs or enhance chondrogenesis in combination with TGFB1 or BMP2 [6]. Chondrogenic hypertrophy of adult MSCs represents the stage of terminal chondrocyte differentiation and is undesired in cartilage regenerative approaches as apoptosis follows and formation of abnormal ECM components and mineralization of the tissue can occur [2]. This resembles processes within the growth plate, where the interplay of several factors, including BMPs, IHH and others, mediates the replacement of cartilage by bone via endochondral ossification. This involves chondrocyte maturation, hypertrophy and subsequent apoptosis, while osteoprogenitor cells differentiate into osteoblasts and replace the cartilage with mineralized bone tissue $[9,10]$. This observation corresponds to the related in vivo data, where MSCs and BMP2 induced tissue hypertrophy and osteophyte formation, when transplanted at orthotopic $[11,12]$ or ectopic $[13,14]$ sites.

The transcription factor sex-determining region Y-type high-mobility-group-box (SOX) 9 (encoded by SOX9), has been identified as one capable of chondrogenic induction, while inhibiting hypertrophic stages in primary MSCs [1517]. Known as a master regulator of chondrogenesis in embryonic cells, SOX9 is needed for chondrogenic mesenchymal condensation in embryonic limb formation [18], and the DNA binding domains of SOX9 directly control expression of several chondrogenic marker proteins, e.g. collagen (COL) type IIa1, COL type IIa2, and aggrecan, among others. It is expressed in all chondroprogenitor cells and chondrocytes, but not in hypertrophic chondrocytes $[17,19]$.

As SOX9 is a transcription factor it can only be delivered efficiently via genetic approaches. The aim of the present study was to explore the effects of adenoviral delivery of $S O X 9$ compared to TGFB1, or IGF1 cDNA or combinations thereof, on chondrogenesis of primary MSCs and to investigate whether the levels and extent of chondrogenic hypertrophy are influenced by the choice of the transgene in an established in vitro aggregate culture model.

\section{Gene therapy for cartilage regeneration}

Gene therapy involves the transfer of genes, or more usually cDNAs, to target cells that will express the transgene. This is accomplished using viral or non-viral vectors that can deliver the transgene to the nucleus of the recipient cell. Gene transfer using non-viral vectors is known as transfection.

Non-viral vectors can be as simple as DNA plasmids, but transfection with plasmids is inefficient. Transfection efficiency can be improved by combining the plasmid with certain types of nanoparticles, by formulating them with a matrix to produce a "gene activated matrix" (GAM) or by engaging a physical stimulus as in electroporation, sonoporation or magnetofection [20]. Even when augmented in these ways, transfection efficiency is usually too low to be useful for cartilage repair as presently envisioned, where the goal is to express chondrogenic morphogens or transcription factors. For this reason, most progress has been made using viral vectors.

Viral vectors exploit the high natural infectivity of viruses [21]. In engineering viruses as vectors, the aim is to remove components of the viral genome that contribute to pathogenicity and replace them with therapeutic cDNAs. Although viral vectors are much more efficient than non-viral vectors, they are more difficult to produce and, when considering human application, they raise more safety issues. The recombinant viruses most commonly used in human gene therapy trials are based upon retroviruses, lentiviruses, adenovirus, and adeno-associated virus (AAV). Recent marketing approvals from the EMA and FDA have gone to gene therapeutics using lentivirus and AAV. In the studies reported here we have used adenovirus because it is highly efficient, straightforward to produce in the laboratory at high titre and typically expresses for around 2-3 weeks, which may be ideal for initiating a sustained regenerative response.

The use of gene transfer to stimulate cartilage repair was first suggested 25 years ago by Evans and Robbins [22]. Since then, a large literature has accumulated with pre-clinical animal models to demonstrate proof of principle using a variety of vectors delivering chondrogenic cDNAs by in vivo and ex vivo strategies [23, 24]. These studies have coincided with the emergence of mesenchymal stromal cells (MSCs) as clinically relevant agents of cartilage repair, and investigations into the use of genetically modified MSCs to regenerate cartilage are popular [25]. Most of these studies have used cDNAs encoding morphogens such as TGF- $\beta$, BMPs- $2,-7$ or 9 , and IGF-1 and, while giving initially favourable results ultimately produce a regenerate that undergoes endochondral ossification. In response to this, the present study uses a construct expressing SOX9 which may not provoke this problem [26-30].

\section{Methods}

Recombinant adenoviral vectors

The adenoviral vectors for TGFB1, IGF1, firefly luciferase $(L U C)$ and green fluorescent protein $(G F P)$ were generated by cre-lox recombination as described earlier 
[31, 32]. The first generation adenoviral vector, serotype 5, carrying a human SOX9 - GFP fusion cDNA (SOX9/ $G F P$ ) was generated using the Ad. Easy system as earlier described [33]. The resulting vectors were designated Ad.SOX9, Ad.TGFB1, Ad.IGF1, Ad.LUC, or Ad.GFP. The suspensions of recombinant adenovirus were prepared by amplification in 293 cells. After this, the suspensions were purified by three consecutive $\mathrm{CsCl}$ gradients [31]. Optical densitometry at $260 \mathrm{~nm}$ and standard plaque assay were used to estimate the viral titers, which ranged between $10^{12}$ and $10^{13}$ particles $/ \mathrm{mL}$.

\section{Cultivation of bone marrow-derived MSCs, adenoviral transduction and aggregate culture}

Bone marrow was received from the proximal femurs of 10 patients, aged 36-65 years (mean age 53), undergoing total hip arthroplasty. The underlying pathology was primary osteoarthritis in all cases and informed written consent was obtained from all volunteers as approved by the institutional review board of the University of Würzburg that agreed to the entire study protocol (number of the approval 82/08). MSC isolation and culture were performed as described earlier [7, 8]. The culture medium for amplification consisted of DME/F12 medium (containing 10\% FBS and 1\% penicillin/ streptomycin), and cells were plated at $2-3 \times 10^{8}$ nucleated cells per $150 \mathrm{~cm}^{2}$ flask (Falcon, Beckton Dickinson Lab ware, Franklin Lakes, NJ). After 3 days unattached cells were removed, and adherent colonies were cultured at $37^{\circ} \mathrm{C}$, in a humidified atmosphere of $95 \%$ air and $5 \%$ $\mathrm{CO}_{2}$ in DME/F-12 medium with $10 \%$ FBS. Changes of the medium were performed every 3-4 days. At the time of confluence (approximately $1.2 \times 10^{6}$ cells $/ 150 \mathrm{~cm}^{2}$ flask), the cultures were washed with phosphate buffered saline (PBS). Then the cultures were infected in $750 \mu \mathrm{L}$ serum-free DMEM for $2 \mathrm{~h}$ at a dose of $5 \times 10^{2}$ infectious particles (ip)/cell of Ad.SOX9, Ad.TGFB1, Ad.IGF1, alone or in combination at $5 \times 10^{2} \mathrm{ip} /$ cell for each vector as described in the respective experiments later. Control groups were infected with similar doses of Ad.GFP, Ad.LUC, or remained uninfected and were maintained in the presence or absence of recombinant human TGF$\beta 1$ protein at $10 \mathrm{ng} / \mathrm{mL}$ ( $\& \& D$ Systems, Minneapolis, MN, USA). After two hours of viral infection, the supernatant was aspirated and replaced with complete DME/ F-12 medium.

The day after infection, MSCs were detached with trypsin (0.05\% trypsin-EDTA (Invitrogen), washed and then placed in pellet culture as described previously $[7,8]$. MSCs were suspended to a concentration of $1 \times 10^{6} \mathrm{cell} / \mathrm{mL}$ in serumfree DMEM containing $1 \mathrm{mM}$ pyruvate, $1 \%$ ITS+ Premix, $37.5 \mu \mathrm{g} / \mathrm{mL}$ ascorbate-2-phosphate and $10^{-7} \mathrm{M}$ dexamethasone (all Sigma, St. Louis, MO), and aliquots of $3 \times 10^{5}$ cells were transferred to polypropylene conical 15-mL-tubes
(Greiner BioOne Int. AG, Kremsmuenster, Austria) and spun in order to induce aggregate formation. Uninfected controls were also maintained in the presence or absence of $10 \mathrm{ng} / \mathrm{mL}$ recombinant human (rh) TGF- $\beta 1$ protein $(\mathrm{R} \& \mathrm{D}$ Systems, Minneapolis, MN, USA). Pellets were cultured at $37{ }^{\circ} \mathrm{C}$, and medium changes were performed every 2-3 days. In addition, rhTGF- $\beta 1$ was also freshly added to the appropriate cultures. Pellets were harvested at various defined time points for further analyses.

\section{Transgene expression analyses}

Green fluorescent cells in monolayer and aggregate culture following transduction were identified by fluorescence microscopy. To quantitatively confirm transduction efficiencies vectors encoding SOX9/GFP or GFP alone we employed fluorescence and light microscopy on five representative high power fields of each of three aggregate midsections for three aggregates per group and time point and quantified the number of green cells relative to the total number of cells. As $S O X 9 / G F P$ is expressed as a fusion construct, GFP + cells identify SOX9 expressing cells in the $S O X 9 / G F P$ group, and allow assessment of the extent and duration of SOX9 transgene expression.

At day 3, 7, and 14 cell lysates of the transduced MSCs in the aggregate culture were collected, frozen at $-80{ }^{\circ} \mathrm{C}$ and analyzed for SOX9 protein production by western blot as described previously [32]. The protein content of each lysate was determined using the Rotiquant according to the instructions of the supplier (Carl Roth $\mathrm{GmbH}$, Karlsruhe, Germany). Twenty $\mu \mathrm{g}$ of protein were boiled for $5 \mathrm{~min}$ in SDS-polyacrylamide gel electrophoresis buffer (10 mM Tris, pH 6.8; 7.5\% glycerol, 10\% SDS, 0.025\% bromphenol blue). Thereafter, proteins were separated by $12 \%$ SDS-PAGE and electrotransferred to nitrocellulose membranes. To inhibit non-specific binding, the membranes were treated with buffer containing $0.1 \%$ Tween 20 , 2\% horse serum, $2.5 \%$ bovine serum albumin (BSA), and $2.5 \%$ milk powder in PBS for $2 \mathrm{~h}$. Then, the membranes were incubated overnight at $4{ }^{\circ} \mathrm{C}$ in $0.1 \%$ Tween $20,1 \%$ horse serum and $1 \%$ milk powder in PBS with the primary human antibody anti-SOX9 (1: 100; Acris Antibodies GmbH, Hiddenhausen, Germany). After 3 wash steps in washing solution $(10 \mathrm{mM}$ Tris, $\mathrm{pH}$ 7.5, $140 \mathrm{mM} \mathrm{NaCl}, 2 \mathrm{mM}$ EDTA, 0.1 Triton X-100, 1\% horse serum, $1 \%$ BSA, and $1 \%$ milk powder), the membrane was incubated for $1 \mathrm{~h}$ with horseradish peroxidaseconjugated anti-rabbit IgG (1:2000; Sigma-Aldrich) using a solution containing in $0.1 \%$ Tween $20,1 \%$ horse serum, $1 \%$ BSA, and $1 \%$ milk powder in PBS. After further washes, signals were detected by chemiluminescence using the ECL system (Amersham Biosciences, GE Healthcare Life Sciences, Freiburg, Germany).

Media conditioned by the respective aggregates over a 24-h period were collected at day 3, 7, 14 and 21 of culture and assayed for TGF- $\beta 1$ or IGF-1 protein 
production using the appropriate commercially available ELISA kits as directed by the supplier (R\&D Systems).

\section{Histology and immunohistochemistry}

For histology, aggregates were fixed in $4 \%$ paraformaldehyde for $1 \mathrm{~h}$, followed by dehydration in graded alcohols, paraffin embedding, sectioning to $4 \mu \mathrm{m}$, and staining with haematoxylin/eosin (H\&E) or alcian blue (Sigma) as described previously [7, 8]. For visualisation of ALP activity, a histochemical assay was performed according to the instructions of the supplier (Sigma).

Immunohistochemistry on alternate sections was performed as described previously [7]. Briefly, following the respective pre-treatments with pepsin $(1 \mathrm{mg} / \mathrm{mL})$, or chondroitinase ABC (Sigma; $5 \mathrm{U} / \mathrm{mL}$ ), or trypsin $(0.25 \%)$ sections were incubated overnight with the following primary antibodies: monoclonal anti-COL type II (Acris Antibodies $\mathrm{GmbH}$, Hiddenhausen, Germany), anti-chondroitin-4sulphate (CS4) (Millipore GmbH, Schwalbach, Germany) or anti-collagen type X (COL type X) (Calbiochem, Bad Soden, Germany). Immunohistodetection was performed by treatment with Advance ${ }^{\mathrm{Tw}}$ HRP link and Advance ${ }^{\mathrm{Tw}}$ HRP enzyme (Dako, Hamburg, Germany) followed by diaminobenzidine staining (DAB kit; Sigma), and slides were finally counterstained with hemalaun (Merck, Darmstadt, Germany). In addition, controls with non-immune Ig G (Sigma) instead of the primary antibodies were also performed.

\section{Annexin 5 assay}

As a marker of hypertrophy and apoptosis annexin 5 expression in the cultures was determined as directed by the supplier (APOAC; Sigma) and previously described $[7,8]$. In brief, the test uses a double labelling with the red fluorochome Cy3.18/Ann5-Cy3 that binds to early apoptotic cells and 6-carboxyfluorescein diacetate (CFDA; non-fluorescent), which is converted to 6carboxyfluorescein (green fluorescent) by living cells. After 10 or 21 days of culture, aggregates were washed with PBS twice and incubated with double labelling staining solution for $10 \mathrm{~min}$, before they were washed again and fixed in $4 \%$ paraformaldehyde before tissue processing to $4 \mu \mathrm{m}$ paraffin sections. Assessment of living and apoptotic cells was performed on representative sections by using a fluorescence microscope with the appropriate green and red filters.

\section{Biochemical assays}

For analysis of cell proliferation in aggregates the CellTiter-Glo ${ }^{\circ}$ Luminescent Cell Viability Assay was performed as directed by the supplier (Promega) and as described earlier [7, 8]. Briefly, for quantitative detection of adenosine 5 '-triphosphate (ATP), which correlates with the number of viable cells, pellets were disrupted using a pellet pestle, mixed with $100 \mu \mathrm{L}$ of CellTiter-Glo reagent, and luminescence was measured after $10 \mathrm{~min}$ using a plate-reading luminometer.

For quantitative assessment of glycosaminoglycan (GAG) content, pellets were digested with papain solution $(1 \mu \mathrm{g} / \mathrm{mL}$, Sigma), and total GAG content was measured by reaction with 1,9-dimethylmethylene blue (DMMB) using the Blyscan ${ }^{\text {Th }}$ Sulfated Glycosaminoglycan Assay (Biocolor Ltd., Newtownabbey, Northern Ireland) as directed by the manufacturer. DNA content of aggregates was also assessed for normalisation, using the Quant-iT $^{\mathrm{Tx}}$ PicoGreen $^{\circ}$ kit as indicated by the supplier (Invitrogen $\mathrm{GmbH}$, Karlsruhe, Germany).

Alkaline phosphatase (ALP) activity was measured densitometrically at $405 \mathrm{~nm}$ as described previously $[7,8]$. Briefly, pellets were dispersed mechanically followed by supplementation with $0.1 \mathrm{~mL}$ of alkaline lysis buffer for $1 \mathrm{~h}$ (0.1 M glycin, $1 \%$ triton X-100, $1 \mathrm{mM} \mathrm{MgCl}, 1 \mathrm{mM} \mathrm{ZnCl} 2$ ), $0.1 \mathrm{~mL}$ of lysis buffer with p-nitrophenylphosphate $(2 \mathrm{mg} /$ $\mathrm{mL}$; Sigma) for $15 \mathrm{~min}$, followed by $50 \mu \mathrm{L} 50 \mathrm{mM} \mathrm{NaOH}$ stop solution. Optical densities were determined at $405 \mathrm{~nm}$ in an ELISA reader. Relative ALP activities were determined using a standard curve made from p-nitrophenol (Sigma), and normalized to the DNA content.

\section{Gene expression analyses}

Total RNA was extracted from MSC aggregates at days 3, 7, 14 and $21.6-10$ pellets per group and time point were pooled and homogenised using a pellet pestle and repeated tituration in $3.5 \mu \mathrm{l} \beta$-mercaptoethanol and $350 \mu \mathrm{l}$ lysis buffer (Invitrogen). Extraction of total RNA was subsequently performed by using separation columns (NucleoSpin RNA II kit; Macherey-Nagel GmbH, Düren, Germany) with a DNase treatment step according to the manufacturer's instructions. For random hexamer primed cDNA synthesis RNA from aggregates of each condition ( $2 \mu \mathrm{g}$ each group) was used utilizing BioScript reverse transcriptase (Bioline $\mathrm{GmbH}$, Luckenwalde, Germany).

Real-time quantitative PCR analyses were performed for a more accurate assessment of mRNA expressions levels of chondrogenic and hypertrophy marker genes as described previously $[7,8]$. The annealing temperatures, sequences and product sizes of forward and reverse primers used for the following genes (HUGO gene symbol): collagen type II alpha 1 (COL2A1), aggrecan $(A C A N)$, SOX9, collagen type $\mathrm{X}$ alpha 1 (COL10A1), alkaline phosphatase $(A L P L)$, are listed in Table 1. Elongation factor $1 \alpha(E E F 1 A 1)$ served as internal control and housekeeping gene. Briefly, one microliter of each cDNA was used as template for amplification in a $50 \mu \mathrm{L}$ reaction volume using BioTaq DNA Polymerase Taq (Bioline $\mathrm{GmbH}$ ) and $50 \mathrm{pmol}$ of gene-specific primers and conditions as listed in Table 1. Real-time PCR was performed with the DNA Engine Opticon system (MJ Research, Waltham, MA) and SYBR Green (Biozym 
Scientific GmbH, Hessisch Oldendorf, Germany) was used as fluorescent dye. Amplicon specificities were finally confirmed by melting curve analyses by gel electrophoresis of test PCR reactions. Quantification of mRNAs was performed using the $\triangle \Delta C T$ method normalised to the expression levels of the housekeeping gene EEF1A1 and relative to values from the control group as described previously $[7,8]$. Each PCR was performed in triplicate on three separate marrow preparations for each independent experiment.

\section{Statistical analysis}

The numerical data from the ELISA, DNA, GAG, ATP, and ALP content, as well as the real-time quantitative RT-PCR analyses were expressed as mean values \pm standard deviation (SD). Each experiment was performed in triplicate or quadruplicate $(N=3-4)$ and repeated on at least 3 and up to 6 individual bone marrow preparations from several different patients $(N=3-6)$. Numerical data on protein level were subjected to variance analysis (one or two factor ANOVA). Statistical significance was determined by student's t-testing. Level of $p<0.05$ was considered significant.

\section{Results}

Transgene expression by genetically modified MSCs in pellet culture

Following transduction with Ad.GFP or Ad.SOX9 vector and placement into pellet culture, expression of the GFP or $S O X / G F P$ transgene was observed by fluorescence microscopy. This showed initially high levels of green fluorescence until day 7 of culture and gradually declining levels of green fluorescence thereafter toward almost background levels by day 21 (Fig. 1a). Untransduced, Ad.TGFB1 or Ad.IGF1 transduced cultures were also maintained and served as controls which were not green fluorescent (Fig. 1a). Quantification of the transduction efficiencies revealed that $>95 \%$ of GFP+ cells were seen at day three in the $S O X 9 / G F P$ and GFP groups respectively, confirming high levels of SOX9 and GFP transgene expression using first generation adenoviral vectors. Thereafter the transgene expression levels declined at days 7,14 and 21 as reflected by decreasing ratios of $\mathrm{GFP}+$ cells in the respective $S O X / G F P(75,45$, and 16\%), or $\operatorname{GFP}(78,56$, and $13 \%)$ groups.

Expression of the SOX9 transgene was further investigated by western blot analyses from lysates of Ad.SOX9 modified pellet cultures, compared to Ad.GFP controls, showing high levels of SOX9 expression at day 3 of culture and subsequently declining levels during the time course, with the GFP controls revealing no visible bands at the same time points (Fig. 1b).

Cultures which were transduced with Ad.TGFB1 alone (TGFB1) or together with Ad.SOX9 (SOX9+TGFB1) were analysed for $24-\mathrm{h}$ accumulation of TGF- $\beta 1$ protein in the conditioned media using ELISA, with GFP modified cultures serving as negative controls (Fig. 1c). While GFP control cultures showed only background levels of expression, high levels of TGF- $\beta 1$ protein production were reached by the TGFB1 and the SOX9 + TGFB1 cultures at day 3 of culture with declining levels thereafter during the 21 day time-course (Fig. 1c). Similarly, expression of the IGF1 transgene was investigated in the cultures infected with Ad.IGF1 alone (IGF1) or together with Ad.SOX9 (SOX9+IGF1). These were analysed for 24-h accumulation of IGF-1 protein in the conditioned media using ELISA, with GFP modified cultures serving as negative controls (Fig. 1d). High levels of IGF-1 protein production were reached by both IGF1 modified cultures (IGF1 and SOX9+IGF1) with values of approximately $40-60 \mathrm{ng} / \mathrm{mL}$ at day 3 , and $20-35 \mathrm{ng} / \mathrm{mL}$ at day 7 of culture with declining

Table 1 Primer sequences and product sizes for real time RT-PCR

\begin{tabular}{|c|c|c|c|}
\hline Gene & RT-PCR primer sequences $\left(5^{\prime}-3^{\prime}\right)$ & Annealing temp. $\left({ }^{\circ} \mathrm{C}\right)$ & Product size (bp) \\
\hline \multicolumn{4}{|c|}{ Chondrogenic marker genes } \\
\hline COL2A1 & $\begin{array}{l}\text { Sense: TTCCCAGGTCAAGATGGTC } \\
\text { Antisense: CTTCAGCACCTGTC CACCA }\end{array}$ & 58 & 374 \\
\hline $50 \times 9$ & $\begin{array}{l}\text { Sense: AGTACCCGCACTTGCACAAC } \\
\text { Antisense: CGTTCTTCACCGACTTCCTC }\end{array}$ & 58 & 263 \\
\hline ACAN & $\begin{array}{l}\text { Sense: TCGAGGACAGCGAGGCC } \\
\text { Antisense: TCGAGGGTGTAGCGTGTAGAGA }\end{array}$ & 54 & 392 \\
\hline \multicolumn{4}{|c|}{ Hypertrophy and osteogenic marker genes } \\
\hline COL10A1 & $\begin{array}{l}\text { Sense: CCCAACACCAAGACACAGTTC } \\
\text { Antisense: GACTTCCGTAGCCTGGTTTTC }\end{array}$ & 54 & 468 \\
\hline$A L P L$ & $\begin{array}{l}\text { Sense: GGAACTCCTGACCCTTGACC } \\
\text { Antisense: CCACCATCTCGGAGAGTGAC }\end{array}$ & 51 & 454 \\
\hline \multicolumn{4}{|c|}{ Internal control } \\
\hline EEF1A1 & $\begin{array}{l}\text { Sense: TGCCCCTCCAGGATGTCTAC } \\
\text { Antisense: CACGGCCCACAGGTACTG }\end{array}$ & 60 & 59 \\
\hline
\end{tabular}




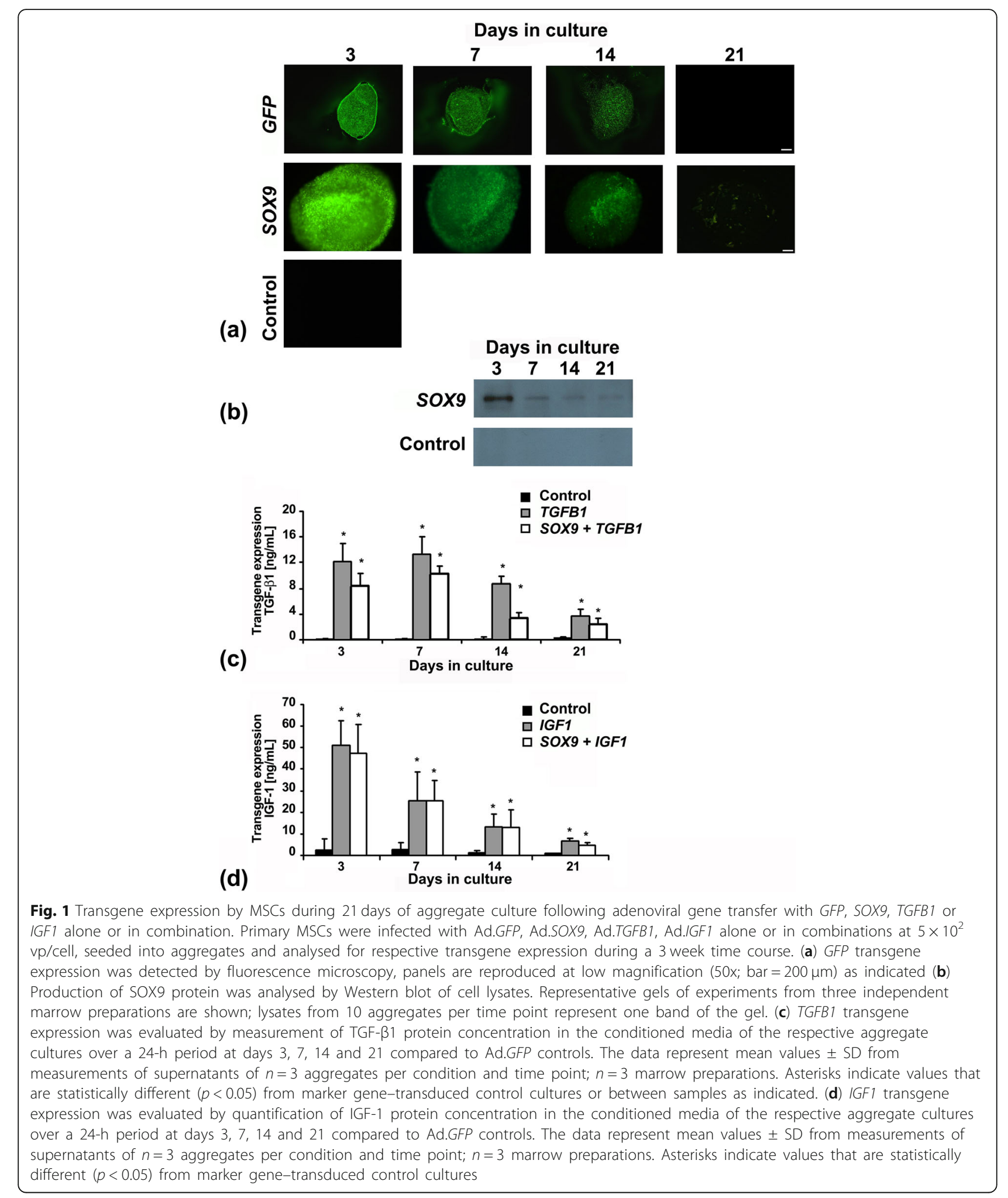

levels thereafter (Fig. 1d). Levels of IGF-1 protein in media conditioned by Ad.GFP infected cultures were low (Fig. 1d), equivalent to the levels observed in the naïve controls (data not shown).
Histology and immunohistochemistry of the chondrogenic phenotype

Cells transduced with GFP were not chondrogenic (Fig. 2a), but genetic modification of MSCs with 


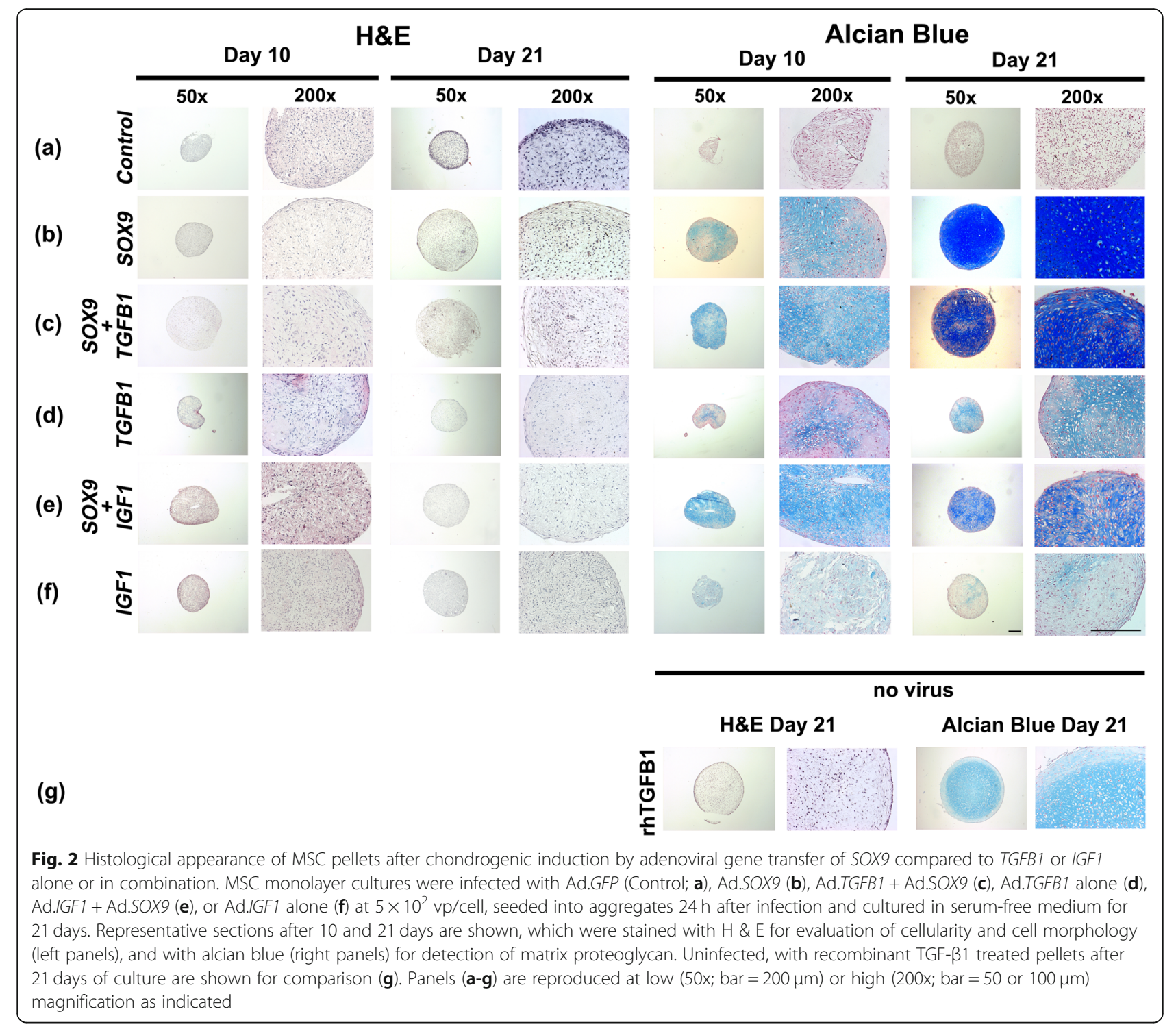

adenoviral vectors encoding SOX9 induced large pellets with abundant proteoglycan accumulation (Fig. 2b). MSCs transduced with TGFB1 (Fig. 2d) displayed a moderate chondrogenic phenotype, but IGF1 alone was not chondrogenic (Fig. 2f). When combined with TGFB1 or $I G F 1$, the chondrogenic response to $S O X 9$ was weaker (Fig. 2c,e).

Immunohistochemistry for COL type II, the main collagen of cartilage, and CS4, one of the small monomers of the polysaccharide fraction of cartilage GAGs, confirmed the results of H\&E and alcian blue staining. Enhanced production of these cartilage matrix components at days 10 and 21 of culture was detected in the aggregate groups SOX9, TGFB1, SOX $9+$ TGFB1 and SOX9+IGF1 (Fig. 3b-e), relative to the GFP (Fig. 3a) and IGF1 alone groups (Fig. 3f), which were not chondrogenic.
Uninfected aggregates maintained in the presence or absence of recombinant human (rh) TGF- $\beta 1(10 \mathrm{ng} / \mathrm{mL})$ or IGF-1 $(50 \mathrm{ng} / \mathrm{mL})$ protein revealed a chondrogenic phenotype in the rhTGF- $\beta 1$ group (Figs. 2 and $3 g$ ) but not the rhIGF-1 group (data not shown); control cultures lacking growth factor supplementation were nonchondrogenic (data not shown).

\section{Hypertrophic differentiation and apoptosis}

Histochemical staining for ALP and immunohistochemical analysis for COL type X (data not shown) were used for evaluating chondrocyte hypertrophy (Fig. 4). In the ALP staining no or only very weak positive staining could be observed in the GFP control pellet cultures (Fig. 4a), as well as the non-chondrogenic IGF1 (Fig. 4f), and the chondrogenic SOX9 (Fig. 4b), and SOX9+IGF1 (Fig. 4e) groups. In contrast, aggregates transduced with 


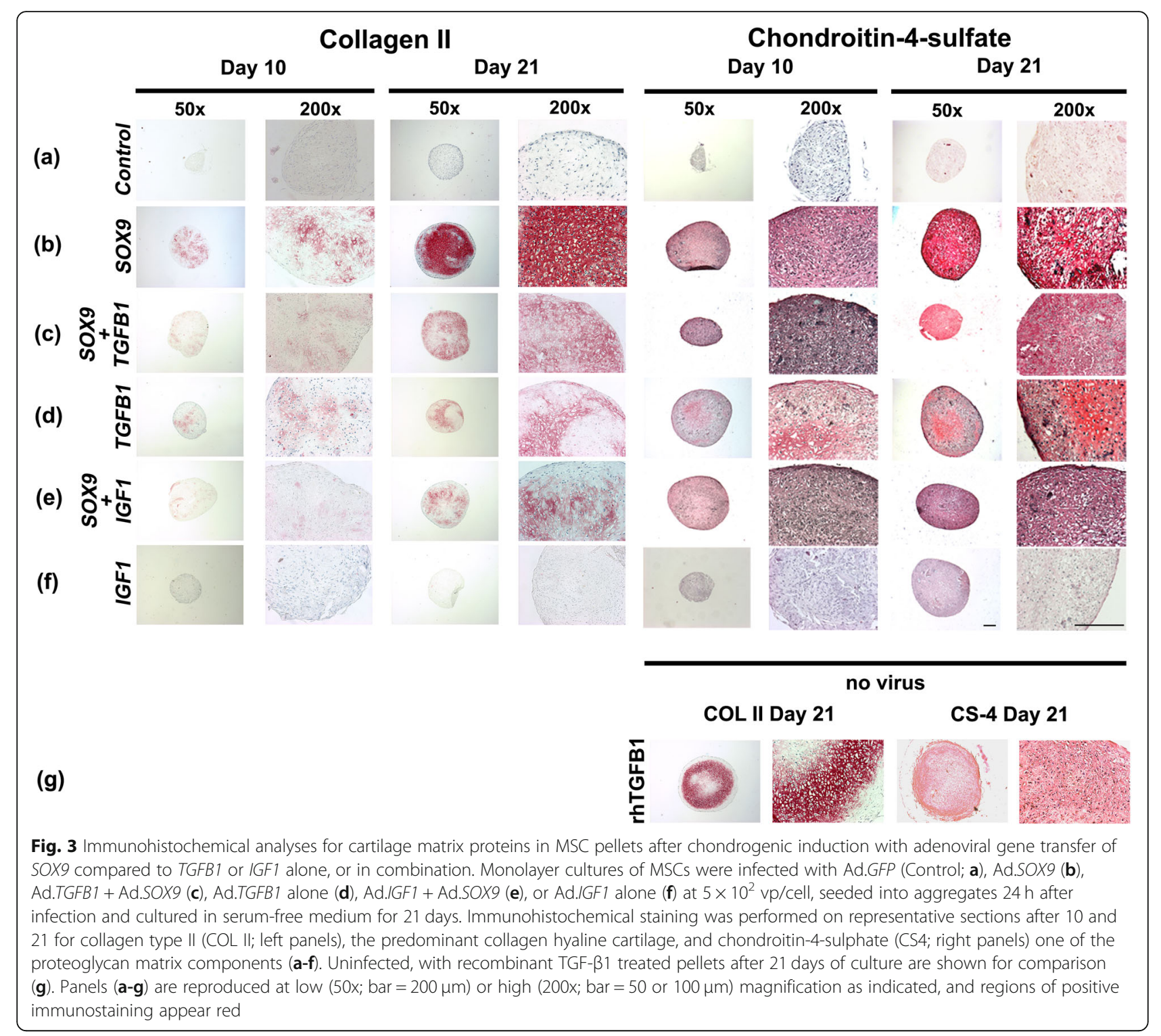

Ad.TGFB1 alone showed abundant blue staining for ALP especially in the area of the outer rim of the aggregates (Fig. 4d). This was also strongly present in the rhTGF- $\beta 1$ group (Fig. 4g). Cultures transduced with Ad.SOX9 together with Ad.TGFB1 (Fig. 4c) revealed weaker ALP staining compared to the Ad.TGFB1 alone group with primarily pericellular staining pattern within the aggregates (Fig. 4d).

Pellet cultures were probed using double fluorescence staining with Ann5-Cy3/6-CFDA to identify living and apoptotic cells (Fig. 5) in untransduced controls and following adenoviral gene transfer of the various gene combinations. In all groups high levels of green fluorescence (viable cells) could be detected after 10 and 21 days of culture (Fig. 5, left panels) without major differences between groups (Fig. 5 a-f). Staining for apoptosis with annexin 5 (Fig. 5; right panels) detected only very few annexin 5 positive cells (red fluorescent) in the control group (a), as well as the SOX9 group (b), while many annexin 5 positive cells were found in all other groups at days 10 and 21 of culture (c-f).

Similar patterns of hypertrophy and apoptosis were observed in the untransduced control aggregates that were maintained in the presence or absence of human recombinant IGF-1 or TGF- $\beta 1$ protein (data not shown).

\section{Biochemical assays - cell proliferation, GAG content and ALP activity}

At day 3 of culture the cell proliferation rate was high in all groups of MSC aggregates, with highest rates being observed in the chondrogenic groups SOX9, SOX9 and TGFB1, TGFB1 alone and SOX9 and IGF1 compared to 


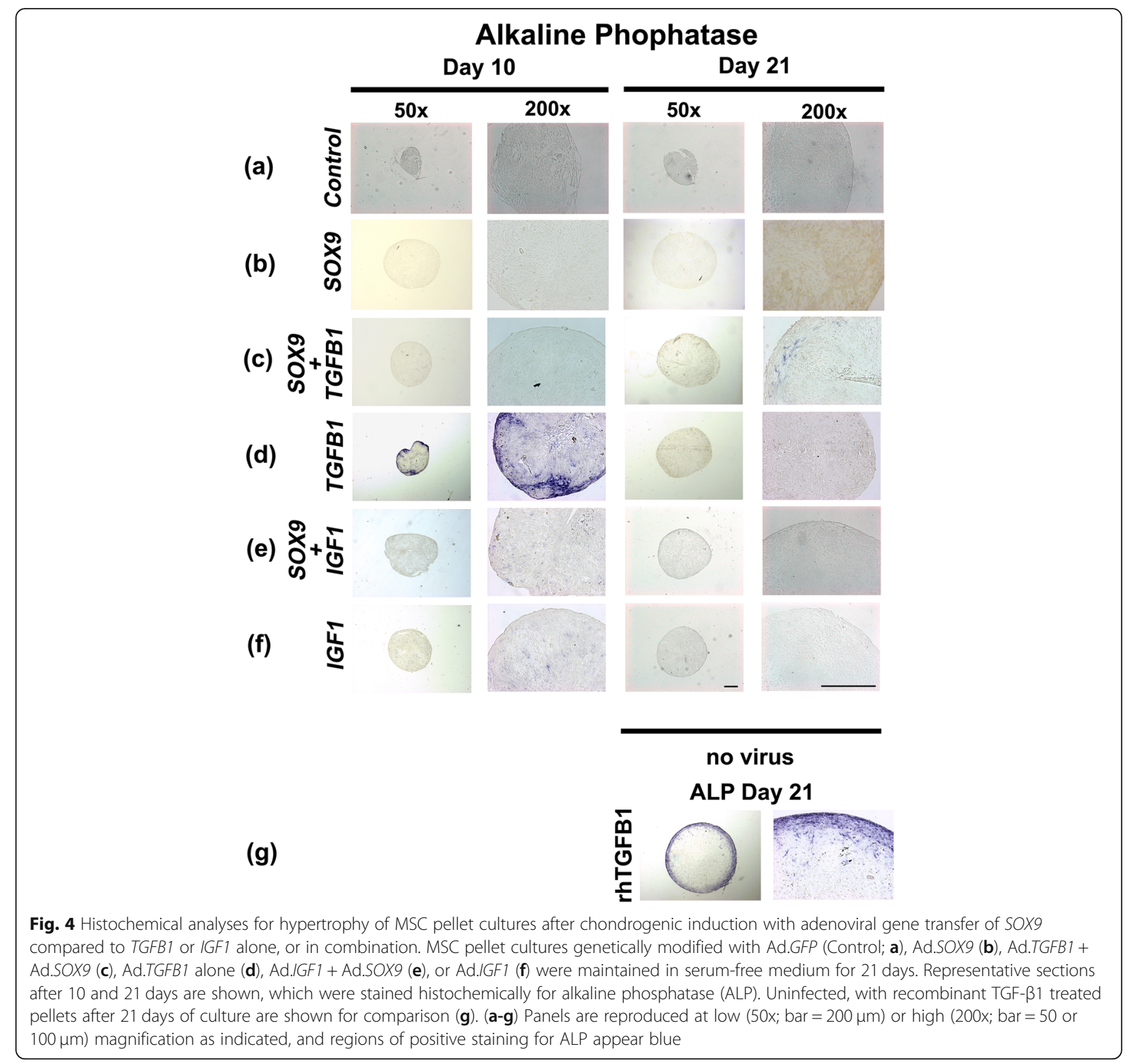

the non-chondrogenic GFP controls and the IGF1 alone group (Fig. 6a). Thereafter, the rate of proliferation decreased in all groups tested with highest values for the SOX $9+$ TGFB1 and SOX9+IGF1 groups at day 7 and without major differences among groups at days 14 and 21 of culture (Fig. 6a).

A similar pattern was observed using the DNA assay, where high values were observed at day 3 in all groups, with highest values being present in the chondrogenic groups SOX9, SOX9+TGFB1, TGFB1 alone and $S O X 9+I G F 1$ compared to the non-chondrogenic GFP control and the IGF1 alone group (Fig. 6b). Thereafter, the DNA content decreased in all groups tested without clear differences between groups at days 7 and 14 of culture, and lowest values for the GFP controls at day 21 (Fig. 6b).

For quantitative comparison and assessment of extracellular matrix synthesis among the transduced groups, GAG levels in the pellet cultures during 21 days in culture were determined (Fig. 6c). The chondrogenic aggregate groups SOX9, SOX9+TGFB1, TGFB1 alone, and SOX9 + IGF1 showed elevated levels of GAG compared to the non-chondrogenic GFP control and the IGF1 alone group during the time-course of 21 days. Differences that reached statistical significance $(p<0.05)$ are marked with asterisks, with the TGFB1 only modified aggregated being the group that reached the significance levels earliest day 3 of culture (Fig. 6c). At days 14 and 


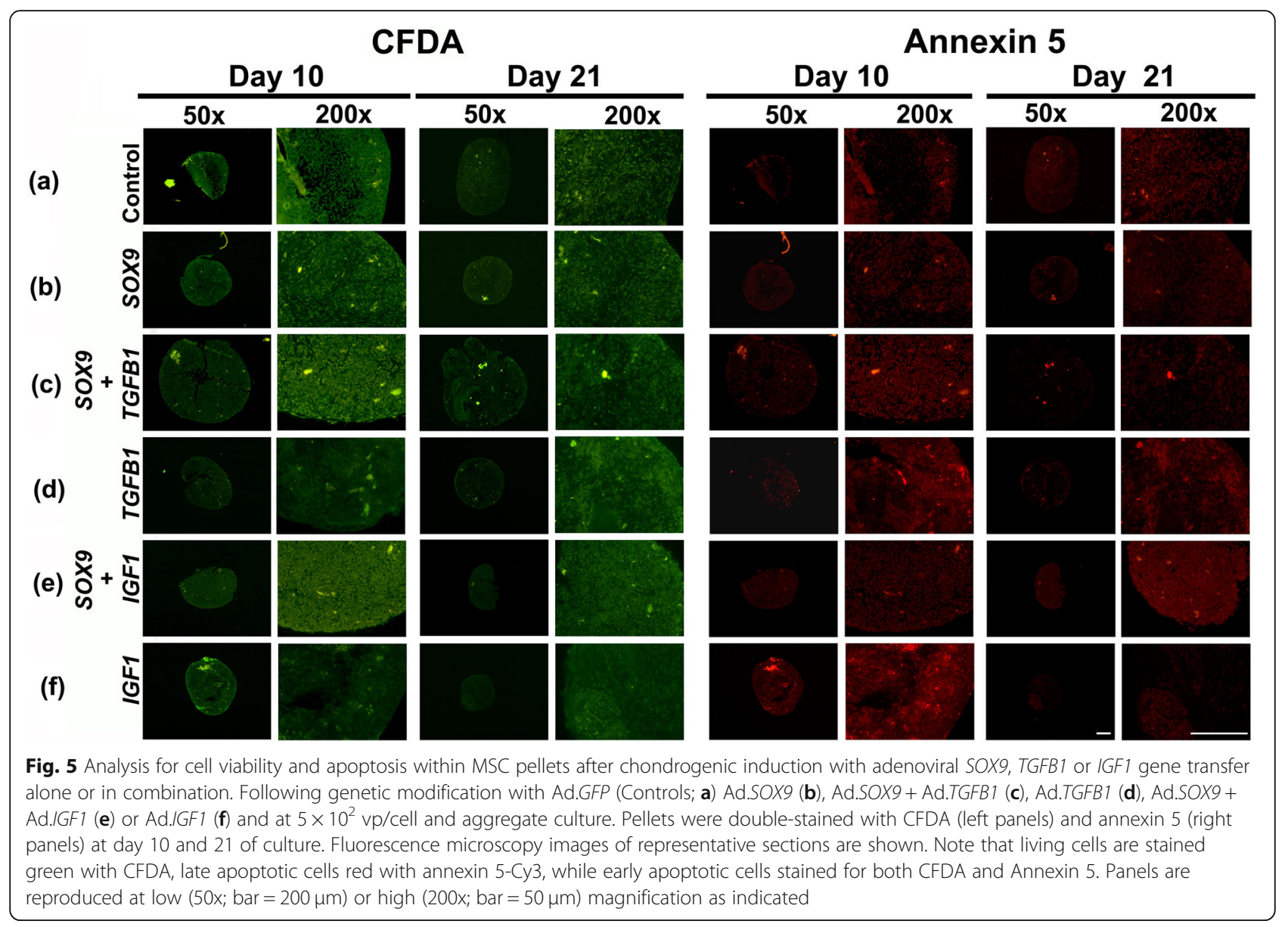

21, no significant differences between levels of GAG among the chondrogenic groups SOX9, SOX9+TGFB1, TGFB1 alone, and $S O X 9+I G F 1$ could be resolved (Fig. 6c).

We analysed ALP activity within the different groups of aggregates as a measure of hypertrophy. ALP was found markedly elevated at all time points in the $\mathrm{SOX} 9+$ TGFB1 pellets and even higher in pellets receiving TGFB1 alone, compared to the GFP controls. There were no significant differences between GFP controls, SOX9, SOX9 + IGF1, and IGF1 alone during the evaluated time-course of 21 days (Fig. 6d).

\section{Real-time RT-PCR analyses - Chondrogenic and}

\section{hypertrophic marker gene expression}

For a more accurate quantification of the expression of marker genes associated with chondrogenesis and hypertrophy, real-time RT-PCR analyses were performed for selected genes (COL2A1, SOX9, ACAN, COL10A1 and $A L P L)$. Expression of marker genes associated with chondrogenesis (COL2A1, SOX9, ACAN) was upregulated in all chondrogenic groups with the highest levels being visible for the SOX9, the SOX9+TGFB1 and the $S O X 9+I G F 1$ groups especially at day 21 of culture (Fig. 7a). Notably, high levels of SOX9 in these groups at day 3 may reflect transgene expression and not only chondrogenic induction.

Genes associated with chondrogenic hypertrophy such as COL10A1 and $A L P L$ were more significantly upregulated in the TGFB1 and SOX9+TGFB1 groups compared to the $S O X 9$ and the $S O X 9+I G F 1$ groups over time, relative to the marker gene controls (Fig. 7b). These results suggest that TGFB1 rather than $S O X 9$ induced a significant hypertrophic response in MSC aggregates at the mRNA level.

\section{Discussion}

Although the potential advantages of MSCs as agents of cartilage regeneration have been recognised for a long time, their deployment in this regard remains problematic [34-37]. Among the challenges is the need to provide a sustained chondrogenic signal to the MSCs while preventing terminal, hypertrophic differentiation with consequent apoptosis and endochondral ossification.

We and others have explored the use of gene transfer as a means of providing self-sustaining chondrogenic stimuli to MSCs [4, 6-8, 23, 38-40]. A number of transgenes, such as those encoding TGF- $\beta$, BMP-2 and BMP- 

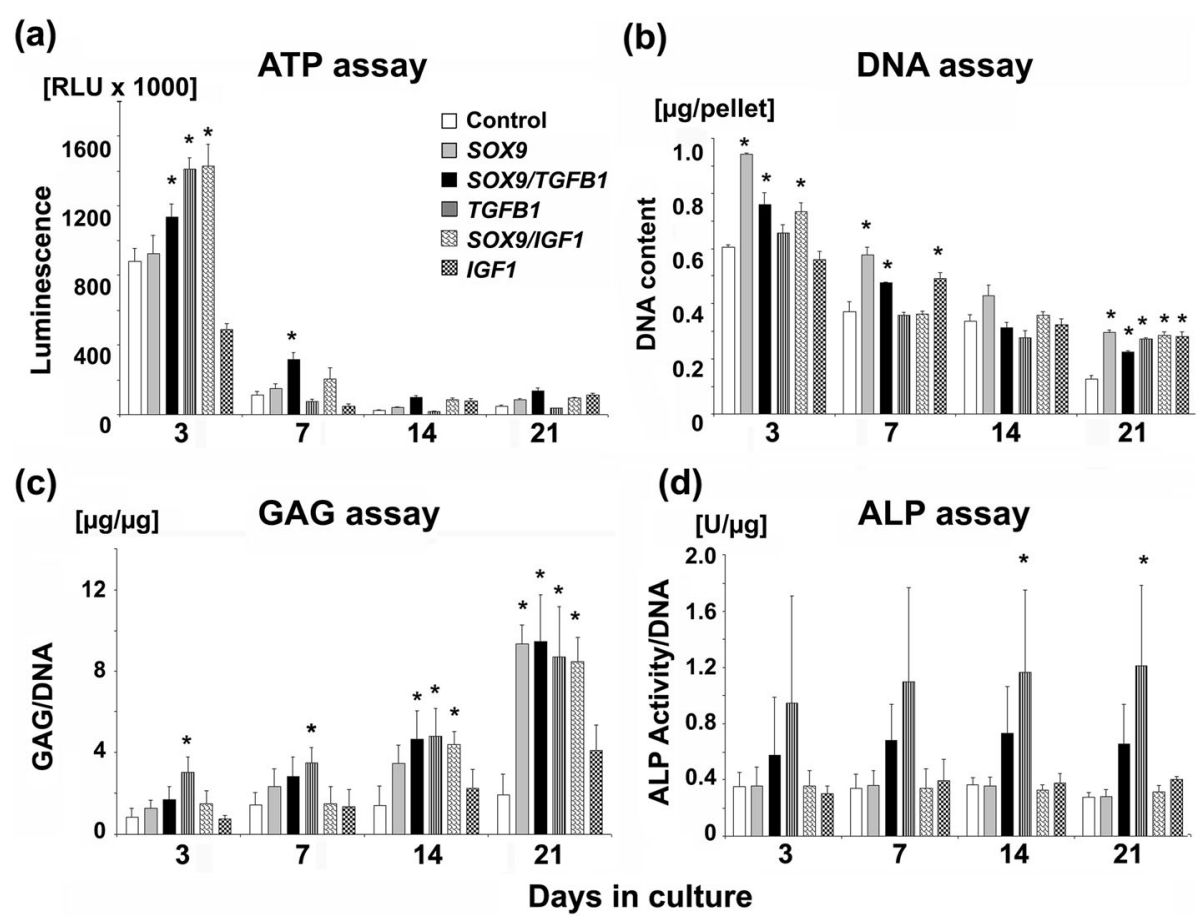

Fig. 6 Biochemical composition of MSCs during three weeks of pellet culture following adenoviral gene transfer with GFP, SOX9, TGFB1 or IGF1 alone or in combination. Primary MSCs were infected with Ad.GFP (Control), Ad.SOX9 (SOX9), Ad.TGFB1 + Ad.SOX9 (SOX9 + TGFB1), Ad.TGFB1 alone (TGFB1), Ad.IGF1 + Ad.SOX9 (SOX9 + IGF1), or Ad.IGF1 alone (IGF1) at $5 \times 10^{2} \mathrm{vp} /$ cell, seeded into aggregate cultures and maintained in serum-free medium for 21 days. At days 3, 7, 14 and 21 biochemical assays were performed to measure (a) cell proliferation by the ATP assay, (b) DNA content, (c) GAG synthesis via GAG/DNA ratios, and (d) ALP activity normalized to the DNA content. (a-d) The data represent mean values \pm SD from $n=3$ aggregates per condition and time point from marrow preparations of $n=3$ different patients. Asterisks indicate values that are statistically different $(p<0.05)$ from marker gene vector-transduced control cultures or between samples

4 have shown success in this endeavour, but in each case there was progression towards hypertrophy [6,7].

The present study shows that transfer of cDNA encoding SOX9 is more effective than TGFB1 in promoting chondrogenesis in pellet culture. Moreover, unlike TGFB1, SOX9 does this without inducing the markers of hypertrophic differentiation during the 21day incubation period. Notably, ALP staining in the TGFB1 group was highest at day 10 of culture, whereas the expression at day 21 was low, which might reflect a phaseal upregulation during osteogenic pathways which are seen during osteogenesis of mesenchymal cells $[1,9]$. Intriguingly, co-transduction of MSCs with SOX9 and TGFB1 reduced the effectiveness of SOX9 both in terms of promoting chondrogenesis and preventing the emergence of markers of hypertrophy. IGF-1 alone, as noted previously, induced neither chondrogenesis nor hypertrophy [6]. Like in previous work [6] the combination groups $(S O X 9+T G F B 1$ or $S O X 9+I G F 1)$ received twice the amount of infectious viral particles, which resulted in comparable amounts of transgene expression for each transgene, however, synergistic effects on the chondrogenic phenotype have not been observed.
Previous authors have studied SOX9 as an agent of chondrogenesis, using MSCs, de-differentiated chondrocytes and iPS cells in this regard [41-43]. Although the results of these studies are largely in line with our data, there are some discrepancies. Kupcsik et al., for instance, only noted increased GAG synthesis in response to SOX9 when the cells were also mechanically stimulated [44]. This may reflect the MSC culture conditions as their study employed human MSCs seeded into a hydrogel whereas we used pellet cultures. Other authors have reported a chondrogenic response only when $S O X 9$ was co-transferred with SOX5 and SOX6 (SOX trio) [45]. Nevertheless, SOX9 clearly merits further study in the context of chondrogenesis and cartilage repair. In vivo experiments support this assessment. Preliminary studies using rabbits suggest a role in cartilage repair for MSCs transduced with Ad.SOX9 and seeded onto a polyglycolic acid scaffold [15].

Because $S O X 9$ is an intracellular protein it is difficult to deliver to target cells by traditional methods. Gene transfer overcomes this barrier. Future clinical translation of this technology will require an appropriate vector. The recombinant adenovirus used in the present study is straightforward to produce and provide 


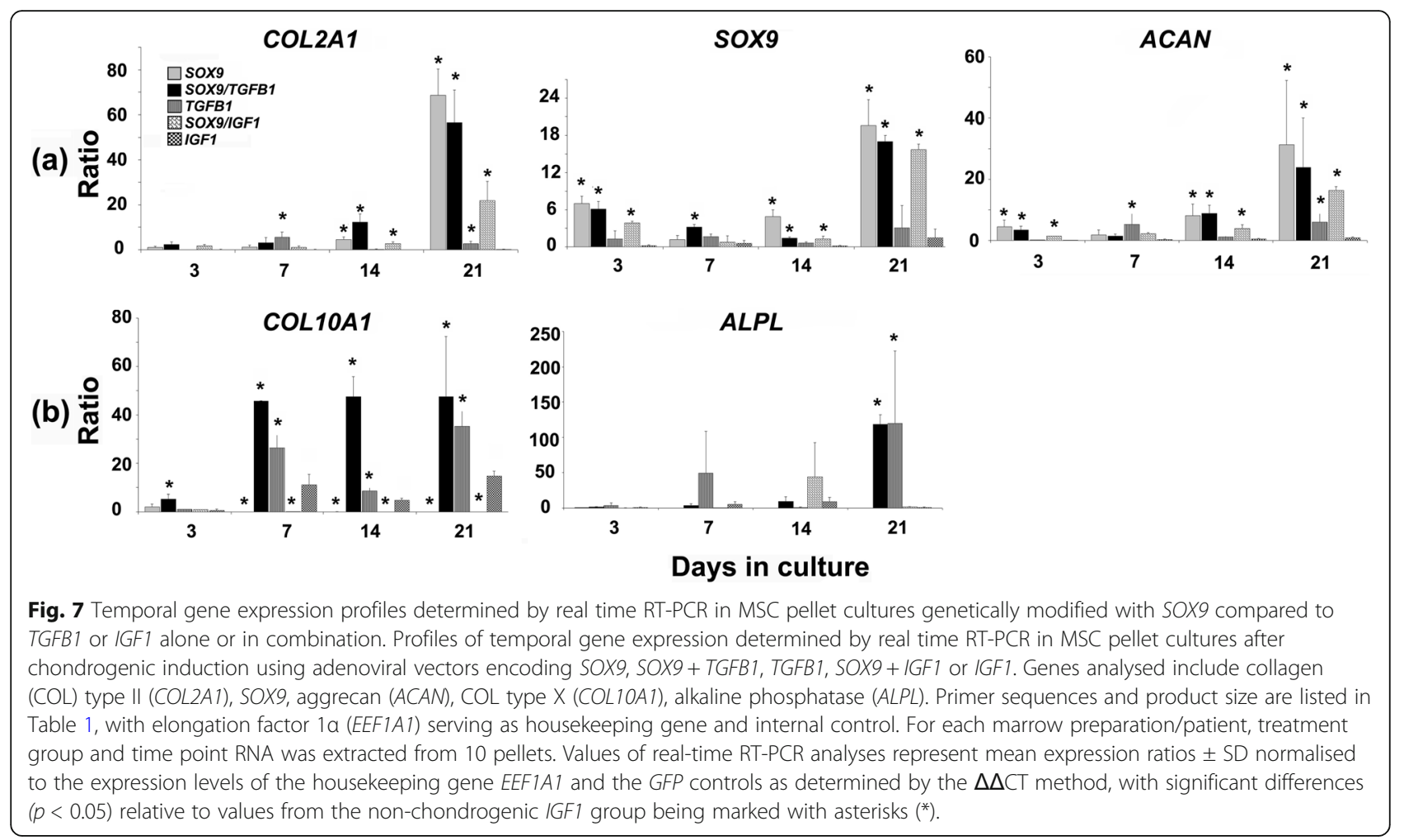

transgene expression for $2-3$ weeks, which may be sufficient to provoke a sustainable regenerative response. Moreover, our data suggest that the effects of SOX9 are sustained and amplified by autocrine effects, as revealed by the persistence of SOX 9 expression in cells after expression from the SOX9-GFP fusion transgene has ceased.

Adenovirus has been widely used in human gene therapy trials which showed this vector to stimulate innate and humoral immune responses that are disadvantages for systemic delivery [46-48]. However, local delivery of the type that would be used for cartilage repair is unlikely to be problematic. Adeno-associated virus (AAV) is increasingly becoming the vector of choice for human gene therapy $[43,49]$. Cucchiarini and Madry have successfully used AAV to deliver SOX9 to chondrocytes and MSCs, with results consistent to those reported in the present paper [50]. A clinical trial in which AAV is injected into joints with osteoarthritis was recently initiated (ClinicalTrials.gov Identifier: NCT02790723).

Daniels et al. could show that SOX9 overexpression via AAV gene transfer to human osteoarthritic articular chondrocytes leads to a significant production of ECM components like proteoglycans and COL type II without affecting the cell proliferation [26]. These findings are consistent with our data showing SOX9 as an effective inducer of chondrogenesis. Interestingly, combined AAV gene transfer of TGFB and SOX9 in bone marrow aspirates could induce chondrogenesis and reduce hypertrophic differentiation [27]. A finding that could not be confirmed by our data showing that genes associated with chondrogenic hypertrophy such as COL10A1 and $A L P L$ were more significantly upregulated in the TGFB1 and SOX9+TGFB1 groups compared to the SOX9 group.

\section{Conclusion}

Adenoviral SOX9 gene transfer induces chondrogenic differentiation of human primary MSCs in pellet culture more effectively than TGFB1 gene transfer with lower levels of chondrocyte hypertrophy after 3 weeks of in vitro culture. This technology might be harnessed to develop methods for allowing sustained chondrogenesis while preventing hypertrophic differentiation, thus leading to improved cartilage repair.

\footnotetext{
Abbreviations

ACAN: Aggrecan core protein gene; Ad: Adenoviral vector; ALP: Alkaline phosphatase; ALPL: ALP gene; ATP: Adenosine 5 triphosphate; BMP: Bone morphogenetic protein; COL: Collagen; COL10A1: COL10 gene; COL2A1: COL2 gene; CS: Chondroitin sulphate; DMMB: Dimethylmethylene blue; EEF1A: Elongation factor 1 alpha gene; GAG: Glycosaminoglycan; GFP: GFP gene; GFP: Green fluorescent protein; IGF1: IGF-1 gene; IGF-1: Insulin like growth factor 1; $1 \mathrm{HH}$ : $1 \mathrm{HH}$ gene; $\mathbb{H H}$ : Indian hedgehog; iPS: Induced pluripotent stem cell; LUC: Firefly luciferase; LUC: LUC gene; MSC: Mesenchymal stem cell; RUNX2: Runt-related transcription factor 2; SOX9: SOX9 gene; SOX9: SRY (sex determining region Y) - box 9; TGFB1: TGF$\beta 1$ gene; TGF- $\beta 1$ : Transforming growth factor $\beta 1$
} 


\section{Acknowledgments}

We are grateful to Viola Zehe, Beate Geyer and Jutta Schneidereit for their excellent technical assistance. We are grateful to Frank Phillips, MD (Chicago, IL, USA) for kindly providing the Ad.SOX9 vector.

\section{Authors' contributions}

All authors have read and approved the manuscript and contributed to the study design, data analysis, interpretation of data and drafting and revision of the manuscript. All data have been generated by AFS, MHW, MW, FG and a data review committee (AFS, MW, MHW, JG, and CHE) analysed and interpreted the data. The authors read and approved the final manuscript.

\section{Funding}

This work was supported in parts by grants STE 1051/3-1 and 3-2 from the Deutsche Forschungsgemeinschaft (DFG) to AFS by grant D-209 to AFS and JG from the Interdisciplinary Center for Clinical Research (IZKF) Würzburg, Germany. This publication was funded by the German Research Foundation (DFG) and the Julius-Maximilians-University Würzburg, Germany, in the funding program Open Access Publishing.

\section{Availability of data and materials}

The datasets used and/or analysed during the current study are available from the corresponding author on reasonable request.

\section{Ethics approval and consent to participate}

Bone marrow was harvested from the surgical waste of femurs undergoing total hip arthroplasty, after informed written consent was given and as approved by the institutional review board of the University of Wuerzburg.

\section{Consent for publication}

Not applicable.

\section{Competing interests}

The authors declare that they have no competing interests.

\section{Author details}

${ }^{1}$ Department of Orthopaedic Surgery, König-Ludwig-Haus, Center for Musculoskeletal Research, Julius-Maximilians-University, Brettreichstrasse 11, D-97074 Würzburg, Germany. ${ }^{2}$ Department of Pathology, Caritas-Hospital, Bad Mergentheim, Germany. ${ }^{3}$ Department of Orthopaedic Trauma, Hand, Plastic and Reconstructive Surgery, University Hospital Würzburg, Würzburg, Germany. ${ }^{4}$ Department of Functional Materials in Medicine and Dentistry, Julius-Maximilians-University, Würzburg, Germany. ${ }^{5}$ Rehabilitation Medicine Research Center, Mayo Clinic, Rochester, MN, USA. ${ }^{6}$ Present address: Department of Orthopaedic, Trauma, Shoulder and Arthroplasty Surgery, Rhön-Klinikum Campus Bad Neustadt, Bad Neustadt a.d. Saale, Germany.

\section{Received: 1 November 2019 Accepted: 12 February 2020}

\section{Published online: 17 February 2020}

\section{References}

1. Kolf CM, Cho E, Tuan RS. Mesenchymal stromal cells. Biology of adult mesenchymal stem cells: regulation of niche, self-renewal and differentiation. Arthritis Res Ther. 2007;9:204.

2. Steinert AF, Ghivizzani SC, Rethwilm A, Tuan RS, Evans $\mathrm{CH}$, Noth U. Major biological obstacles for persistent cell-based regeneration of articular cartilage. Arthritis Res Ther. 2007;9:213.

3. Evans $\mathrm{CH}$, Huard J. Gene therapy approaches to regenerating the musculoskeletal system. Nat Rev Rheumatol. 2015;11:234-42.

4. Madry H, Orth P, Cucchiarini M. Gene therapy for cartilage repair. Cartilage. 2011;2:201-25

5. Steinert AF, Noth U, Tuan RS. Concepts in gene therapy for cartilage repair. Inj. 2008;39(Suppl 1):S97-113.

6. Steinert AF, Palmer GD, Pilapil C, Noth U, Evans CH, Ghivizzani SC. Enhanced in vitro chondrogenesis of primary mesenchymal stem cells by combined gene transfer. Tissue Eng Part A. 2009;15:1127-39.

7. Steinert AF, Proffen B, Kunz M, Hendrich C, Ghivizzani SC, Noth U, et al. Hypertrophy is induced during the in vitro chondrogenic differentiation of human mesenchymal stem cells by bone morphogenetic protein-2 and bone morphogenetic protein-4 gene transfer. Arthritis Res Ther. 2009;11: R148.
8. Steinert AF, Weissenberger M, Kunz M, Gilbert F, Ghivizzani SC, Gobel S, et al. Indian hedgehog gene transfer is a chondrogenic inducer of human mesenchymal stem cells. Arthritis Res Ther. 2012;14:R168.

9. Goldring MB, Tsuchimochi K, ljiri K. The control of chondrogenesis. J Cell Biochem. 2006;97:33-44.

10. Mwale F, Stachura D, Roughley P, Antoniou J. Limitations of using aggrecan and type $X$ collagen as markers of chondrogenesis in mesenchymal stem cell differentiation. J Orthop Res. 2006;24:1791-8.

11. Gelse K, von der Mark K, Aigner T, Park J, Schneider H. Articular cartilage repair by gene therapy using growth factor-producing mesenchymal cells. Arthritis Rheum. 2003:48:430-41.

12. Sieker JT, Kunz M, Weissenberger M, Gilbert F, Frey S, Rudert M, et al. Direct bone morphogenetic protein 2 and Indian hedgehog gene transfer for articular cartilage repair using bone marrow coagulates. Osteoarthr Cartil. 2015;23:433-42.

13. Pelttari K, Winter A, Steck E, Goetzke K, Hennig T, Ochs BG, et al. Premature induction of hypertrophy during in vitro chondrogenesis of human mesenchymal stem cells correlates with calcification and vascular invasion after ectopic transplantation in SCID mice. Arthritis Rheum. 2006;54:3254-66.

14. De Bari C, Dell'Accio F, Luyten FP. Failure of in vitro-differentiated mesenchymal stem cells from the synovial membrane to form ectopic stable cartilage in vivo. Arthritis Rheum. 2004;50:142-50.

15. Cao L, Yang F, Liu G, Yu D, Li H, Fan Q, et al. The promotion of cartilage defect repair using adenovirus mediated Sox9 gene transfer of rabbit bone marrow mesenchymal stem cells. Biomater. 2011;32:3910-20.

16. Dy $P$, Wang W, Bhattaram P, Wang Q, Wang L, Ballock RT, et al. Sox9 directs hypertrophic maturation and blocks osteoblast differentiation of growth plate chondrocytes. Dev Cell. 2012;22:597-609.

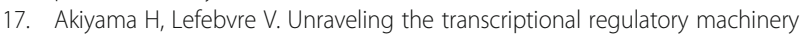
in chondrogenesis. J Bone Miner Metab. 2011;29:390-5.

18. Bi W, Deng JM, Zhang Z, Behringer RR, de Crombrugghe B. Sox9 is required for cartilage formation. Nat Genet. 1999;22:85-9.

19. Zhao Q, Eberspaecher H, Lefebvre V, De Crombrugghe B. Parallel expression of Sox9 and Col2a1 in cells undergoing chondrogenesis. Dev Dyn. 1997;209: 377-86

20. Slivac I, Guay D, Mangion M, Champeil J, Gaillet B. Non-viral nucleic acid delivery methods. Expert Opin Biol Ther. 2017;17:105-18.

21. Chen $\mathrm{YH}$, Keiser MS, Davidson BL. Viral vectors for gene transfer. Curr Protoc Mouse Biol. 2018;8:e58.

22. Evans $\mathrm{CH}$, Robbins PD. Possible orthopaedic applications of gene therapy. J Bone Joint Surg Am. 1995;77:1103-14.

23. Evans $\mathrm{CH}$, Ghivizzani SC, Smith P, Shuler FD, Mi Z, Robbins PD. Using gene therapy to protect and restore cartilage. Clin Orthop Relat Res. 2000; 379(Suppl):S214-9.

24. Bellavia D, Veronesi F, Carina V, Costa V, Raimondi L, De Luca A, et al. Gene therapy for chondral and osteochondral regeneration: is the future now? Cell Mol Life Sci. 2018;75:649-67.

25. Mesure B, Menu P, Venkatesan JK, Cucchiarini M, Velot É. Biomaterials and gene therapy: a smart combination for MSC musculoskeletal engineering. Curr Stem Cell Res Ther. 2019;14:337-43.

26. Daniels O, Frisch J, Venkatesan JK, Rey-Rico A, Schmitt G, Cucchiarini M. Effects of $\mathrm{rAAV}$-mediated sox9 overexpression on the biological activities of human osteoarthritic articular chondrocytes in their intrinsic three-dimensional environment. J Clin Med. 2019;8. https://doi.org/10.3390/jcm8101637.

27. Tao K, Rey-Rico A, Frisch J, Venkatesan JK, Schmitt G, Madry H, et al. Effects of combined rAAV-mediated TGF- $\beta$ and sox9 gene transfer and overexpression on the metabolic and chondrogenic activities in human bone marrow aspirates. J Exp Orthop. 2017;4. https://doi.org/10.1186/ s40634-017-0077-5.

28. Tao K, Rey-Rico A, Frisch J, Venkatesan JK, Schmitt G, Madry H, et al. rAAVmediated combined gene transfer and overexpression of TGF- $\beta$ and SOX9 remodels human osteoarthritic articular cartilage. J Orthop Res. 2016;34: 2181-90.

29. Tao K, Frisch J, Rey-Rico A, Venkatesan JK, Schmitt G, Madry H, et al. Cooverexpression of TGF- $\beta$ and SOX9 via rAAV gene transfer modulates the metabolic and chondrogenic activities of human bone marrow-derived mesenchymal stem cells. Stem Cell Res Ther. 2016;7. https://doi.org/10.1186/ s13287-016-0280-9.

30. Cucchiarini M, Terwilliger EF, Kohn D, Madry H. Remodelling of human osteoarthritic cartilage by FGF-2, alone or combined with Sox9 via rAAV gene transfer. J Cell Mol Med. 2009;13:2476-88. 
31. Hardy S, Kitamura M, Harris-Stansil T, Dai Y, Phipps ML. Construction of adenovirus vectors through Cre-lox recombination. J Virol. 1997;71:1842-9.

32. Haddad-Weber M, Prager P, Kunz M, Seefried L, Jakob F, Murray MM, et al. BMP12 and BMP13 gene transfer induce ligamentogenic differentiation in mesenchymal progenitor and anterior cruciate ligament cells. Cytotherapy. 2010;12:505-13.

33. Paul R, Haydon RC, Cheng H, Ishikawa A, Nenadovich N, Jiang W, et al. Potential use of Sox9 gene therapy for intervertebral degenerative disc disease. Spine (Phila Pa 1976). 2003;28:755-63.

34. Barry F. MSC therapy for osteoarthritis: an unfinished story. J Orthop Res. 2019:37:1229-35

35. Goldberg A, Mitchell K, Soans J, Kim L, Zaidi R. The use of mesenchymal stem cells for cartilage repair and regeneration: a systematic review. J Orthop Surg Res. 2017;12:39.

36. Savkovic V, Li H, Seon JK, Hacker M, Franz S, Simon JC. Mesenchymal stem cells in cartilage regeneration. Curr Stem Cell Res Ther. 2014;9:469-88.

37. Harrell CR, Markovic BS, Fellabaum C, Arsenijevic A, Volarevic V. Mesenchymal stem cell-based therapy of osteoarthritis: current knowledge and future perspectives. Biomed Pharmacother. 2019;109:2318-26.

38. Madry H, Cucchiarini M, Terwilliger EF, Trippel SB. Recombinant adenoassociated virus vectors efficiently and persistently transduce chondrocytes in normal and osteoarthritic human articular cartilage. Hum Gene Ther. 2003;14:393-402.

39. Madry H, Weimer A, Kohn D, Cucchiarini M. Tissue engineering for articular cartilage repair improved by gene transfer. Current concepts. Orthopade. 2007;36:236-47.

40. Evans CH, Palmer G, Pascher A, Steinert A, Betz O, Ghivizzani SC. Genetically enhanced tissue engineering without cell culture or manufactured scaffolds. In: Grodzinsky A, Sandell L, editors. Orthopaedic tissue engineering. Rosemont, IL: AAOS; 2003.

41. Diederichs S, Gabler J, Autenrieth J, Kynast KL, Merle C, Walles H, et al. Differential regulation of SOX9 protein during Chondrogenesis of induced pluripotent stem cells versus Mesenchymal stromal cells: a shortcoming for cartilage formation. Stem Cells Dev. 2016;25:598-609.

42. Venkatesan JK, Ekici M, Madry H, Schmitt G, Kohn D, Cucchiarini M. SOX9 gene transfer via safe, stable, replication-defective recombinant adenoassociated virus vectors as a novel, powerful tool to enhance the chondrogenic potential of human mesenchymal stem cells. Stem Cell Res Ther. 2012;3:22.

43. Venkatesan JK, Gardner O, Rey-Rico A, Eglin D, Alini M, Stoddart MJ, et al. Improved Chondrogenic differentiation of rAAV SOX9-modified human MSCs seeded in fibrin-polyurethane scaffolds in a hydrodynamic environment. Int J Mol Sci. 2018;19.

44. Kupcsik L, Stoddart MJ, Li Z, Benneker LM, Alini M. Improving chondrogenesis: potential and limitations of SOX9 gene transfer and mechanical stimulation for cartilage tissue engineering. Tissue Eng Part A. 2010;16:1845-55.

45. Liu CF, Lefebvre $V$. The transcription factors SOX9 and SOX5/SOX6 cooperate genome-wide through super-enhancers to drive chondrogenesis. Nucleic Acids Res. 2015:43:8183-203.

46. Evans $\mathrm{CH}$, Robbins PD, Ghivizzani SC, Wasko MC, Tomaino MM, Kang R, et al. Gene transfer to human joints: progress toward a gene therapy of arthritis. Proc Natl Acad Sci U S A. 2005;102:8698-703.

47. Evans $\mathrm{CH}$, Robbins PD. Gene therapy for arthritis. Expert Opin Investig Drugs. 1997;6:837-40.

48. Evans $\mathrm{CH}$, Ghivizzani SC, Oligino TA, Robbins PD. Future of adenoviruses in the gene therapy of arthritis. Arthritis Res. 2001;3:142-6.

49. Coura Rdos S, Nardi NB. The state of the art of adeno-associated virus-based vectors in gene therapy. Virol J. 2007:4:99

50. Cucchiarini M, Orth P, Madry H. Direct rAAV SOX9 administration for durable articular cartilage repair with delayed terminal differentiation and hypertrophy in vivo. J Mol Med (Berl). 2013;91:625-36.

\section{Publisher's Note}

Springer Nature remains neutral with regard to jurisdictional claims in published maps and institutional affiliations.

\section{Ready to submit your research? Choose BMC and benefit from:}

- fast, convenient online submission

- thorough peer review by experienced researchers in your field

- rapid publication on acceptance

- support for research data, including large and complex data types

- gold Open Access which fosters wider collaboration and increased citations

- maximum visibility for your research: over $100 \mathrm{M}$ website views per year

At $\mathrm{BMC}$, research is always in progress.

Learn more biomedcentral.com/submissions 